\title{
Frontiers in Life Science
}

In the five years since its inception, HFSP Journal has made great progress. The journal has established itself as a well-regarded quarterly, publishing cutting-edge research at the interface of life and other advanced sciences. It gained its first impact factor last summer-an impressive 1.786 reflecting a very high standard of research published in the inaugural volumes. The paper of Riedel-Kruse et al. (2007), "How molecular motors shape the flagellar beat" and the study of Amitai et al. (2007), "Latent evolutionary potentials under the neutral mutational drift of an enzyme" are but two highlights among many.

Now the journal is taking another step forward. In 2011, HFSP Journal will become Frontiers in Life Science and will be published by Taylor \& Francis. After the current issue, $\mathrm{Hu}-$ man Frontier Science Program will no longer manage the journal. The editorin-chief, however, will continue to have complete control over editorial policy.

What differences will you see? First, the journal will move to Taylor \& Francis' InformaWorld platform, where articles will be published in PDF and HTML and in advance of the printed issue whenever possible. Online files of the journal's first four volumes will transfer across to Informa-
World and readers will benefit from sophisticated tools such as RSS content feeds and social bookmarks to enable easy linking to blogs and reference management platforms. Authors will still be able to pay for papers to become open access on publication. And the journal will continue to appear in both printed and online form.

For the immediate future, submissions should be directed to the editorial manager (http://www. editorialmanager.com/hfspj). Later in the year, they will transfer to a dedicated ScholarOne Manuscripts site. We will contact authors nearer the time to explain how this will work.

The Taylor \& Francis Group has a long tradition of publishing in life science. Garland Science's Molecular Biology of the Cell, now in its fourth edition, has been a phenomenally popular text. It forms part of an extensive book program, which is complemented by research journals including Critical Reviews in Biochemistry and Molecular Biology, Molecular Membrane Biology, Xenobiotica, Animal Biotechnology, Growth Factors, Microcirculation, Biocatalysis and Biotransformation, Critical Reviews in Microbiology, Artificial Cells, Blood Substitutes and Biotechnology, Food Biotechnology, and Nucleosides, Nucleotides and Nucleic Acids.

\section{ACKNOWLEDGMENT}

We would like to thank everyone for the hard work and initiative, which has brought the journal this far-and look forward to a bright, exciting future for Frontiers in Life Science!

\section{REFERENCES}

Amitai, G, Gupta, RD, and Tawfik, DS (2007).

"Latent evolutionary potentials under the

neutral mutational drift of an enzyme." HFSP J. 1, 67-78.

Riedel-Kruse, IH, Hilfinger, A, Howard, J, and Jülicher, F (2007). "How molecular motors shape the flagellar beat." HFSP J. 1, 192-208.

\section{Rod Cookson}

Taylor \& Francis, 4 Park Square, Milton Park, Abingdon, Oxfordshire, OX14 4RN, United

Kingdom

Valerie Ferrier HFSP Publishing, 12 Quai St. Jean, 67000 Strasbourg, France

Arturo Falaschi

HFSP Publishing, 12 Quai St. Jean, 67000 Strasbourg, France 